\title{
Depth Cues and Mouse-Based 3D Target Selection
}

\author{
Robert J. Teather \\ McMaster University \\ teather@mcmaster.ca
}

\author{
Wolfgang Stuerzlinger \\ York University \\ wolfgang@cse.yorku.ca
}

\begin{abstract}
We investigated mouse-based 3D selection using one-eyed cursors, evaluating stereo and head-tracking. Stereo cursors significantly reduced performance for targets at different depths, but the one-eyed cursor yielded some discomfort.
\end{abstract}

\section{Author Keywords}

Mouse, stereo display, head-tracking, one-eyed cursor.

\section{ACM Classification Keywords}

H.5.2 [Information Interfaces and Presentation]: User Interfaces - input devices, interaction styles.

\section{INTRODUCTION}

Recent work on screen-space 3D selection [2] reinforced the benefits of the "one-eyed" cursor [3] to eliminate stereo conflicts. Other research indicates that one-eyed cursors may cause eye fatigue [1] and hinder performance relative to stereo cursors. We re-evaluate the one-eyed cursor in situations where depth is irrelevant to assess its negative effects in isolation from its benefits, (e.g., remote targets).

\section{EXPERIMENT}

We used a 3D version of ISO 9241-9 [2] with 16 participants and NVidia 3DVision Pro for stereo. Five OptiTrack S250e cameras were used for head tracking.

The software depicted the inside of a wooden crate with target spheres on wooden cylinders (Figure 1), in either stereo or mono, with or without head tracking, and with a stereo 3D or one-eyed cursor. In mono view, the same image ( 0 disparity) was presented to both eyes. The oneeyed cursor was only displayed to the dominant eye.

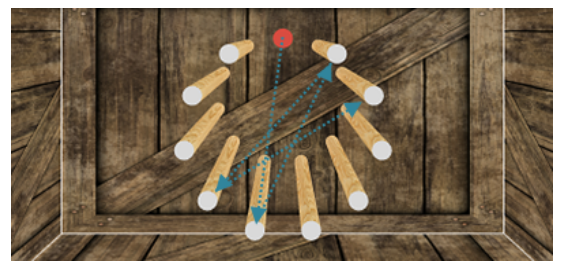

Figure 1. Experimental software depicting 11 targets. Arrows added to illustrate the ordering of the first four targets.

Permission to make digital or hard copies of part or all of this work for personal or classroom use is granted without fee provided that copies are not made or distributed for profit or commercial advantage and that copies bear this notice and the full citation on the first page. Copyrights for third-party components of this work must be honored. For all other uses, contact the Owner/Author.

Copyright is held by the owner/author(s).

SUI '14, Oct 04-05 2014, Honolulu, HI, USA

ACM 978-1-4503-2820-3/14/10.

http://dx.doi.org/10.1145/2659766.2661221
Participants clicked the red target with the mouse. Each click advanced the target by the pattern shown in Figure 1.

The experiment used the following within-subjects factors:

$$
\begin{aligned}
& \text { Stereo Display: Stereo-On, Stereo-Off (i.e., mono) } \\
& \text { Head-Tracking: HT-On, HT-Off } \\
& \text { Cursor: STC (stereo cursor), OEC (one-eyed cursor) } \\
& \text { Target Size: } 0.5,0.75,1.0 \mathrm{~cm} \\
& \text { Target Distance: } 3.5,7.5,9.5 \mathrm{~cm} \\
& \text { Target Depth: }-10,0,+10 \mathrm{~cm}
\end{aligned}
$$

Stereo, head-tracking, and cursor were counterbalanced by a Latin square. Target size, distance, and depth were random for each target circle. There were 12 recorded selection trials per circle. Thus there were $2 \times 2 \times 2 \times 3 \times 3$ $\times 3 \times 12=2592$ trials per participant. We only report "screen-projected" throughput [2] due to space constraints.

\section{RESULTS}

There was a significant interaction between stereo, depth, and cursor $\left(F_{2,30}=12.4, p<.001\right)$, see Figure 2: the STC $0 \mathrm{~cm}$ conditions are better than the $\mathrm{STC}+10 \mathrm{~cm}$ or $-10 \mathrm{~cm}$ conditions, but not the OEC conditions. The best stereo-off conditions (both $\mathrm{STC}$ at $+10 \mathrm{~cm}$ ) were higher than the stereo-on at both -10 and $+10 \mathrm{~cm}$ target depths. There was no difference in the stereo-off conditions.

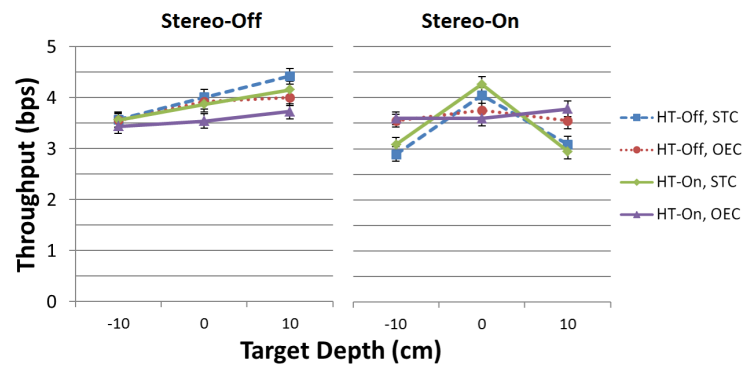

Figure 2. Throughput by condition. Error bars show $\pm 1 S E$.

\section{CONCLUSION}

The stereo cursor significantly hurt performance for targets at different depths. The one-eyed cursor eliminated this effect, but had a small negative effect in mono view.

\section{REFERENCES}

1. Schemali, L. and Eisemann, E., Design and evaluation of mouse cursors in a stereoscopic desktop environment, Proc. IEEE 3DUI 2014, 67-70.

2. Teather, R. J. and Stuerzlinger, W., Pointing at 3D target projections using one-eyed and stereo cursors, Proc. ACM CHI 2013, 159 - 168.

3. Ware, C. and Lowther, K., Selection using a one-eyed cursor in a fish tank VR environment, ACM TOCHI, 4, 1997, 309-322. 